\title{
Prognostic value of expression of molecular markers in adenoid cystic cancer of the salivary glands compared with lymph node metastasis: a retrospective study
}

Seok Ki Lee ${ }^{1}$, Min Su Kwon², Yoon Se Lee ${ }^{3}$, Seung-Ho Choi², Sang Yoon Kim², Kyoung Ja Cho ${ }^{4}$ and Soon Yuhl Nam²

\begin{abstract}
Background: Adenoid cystic cancer arising in the salivary glands has distinctive features such as perineural invasion, distant metastasis, and a variable prognosis. In salivary gland cancer, c-kit, EGFR, and VEGF are representative molecular markers that may predict remnant and recurrent tumors. In this study, the expression of c-kit, EGFR, and VEGF in adenoid cystic cancer was evaluated, and the relationships between the expression of these markers and the clinical findings were investigated.

Methods: The medical records of 48 patients who were treated for parotid adenoid cystic cancer from January 1990 to January 2006 were reviewed. The tumor location, size, histological subtypes, perineural invasion, the resected margin status, and lymph node metastasis were assessed. Immunohistochemical staining and semiquantitative analysis of c-kit, EGFR and VEGF were performed. The relationship between the expression of each marker and the clinicopathological factors were analyzed.

Results: Positive c-kit immunostaining was present in 45 patients (94\%), with weak positivity $(+1)$ in 23 , moderate positivity (+2) in 19 and strong positivity (+3) in three. Positive EGFR immunostaining was observed in 27 (56\%), with weak positivity $(+1)$ in 19 and moderate positivity $(+2)$ in eight with no strong positive staining. Positive VEGF immunostaining was present in 42 patients $(88 \%)$ with weak positivity $(+1)$ in 12 , moderate positivity $(+2)$ in 17 , and strong positivity $(+3)$ in 13 . Only the expression of VEGF was significantly higher in parotid gland tumors than in any other gland $(P=0.032)$. Marginal involvement was associated with strong VEGF expression $(P=0.02)$. No marker was significantly correlated with recurrence or the survival rate. Lymph node status was related to the survival rate.

Conclusions: The expression of c-kit, EGRF, and VEGF had no predictive value for recurrence or the prognosis of adenoid cystic cancer. Only the lymph node status was related to the prognosis.

Keywords: Salivary gland cancer, Adenoid cystic cancer, c-kit, Epithelial growth factor receptor, Vascular endothelial growth factor, Lymph node metastasis
\end{abstract}

\footnotetext{
* Correspondence: synam@amc.seou.kr

${ }^{2}$ Department of Otolaryngology, Asan Medical Center, University of Ulsan, College of Medicine, 388-1 Pungnap-2dong, Songpa-gu, Seoul 138-736,

South Korea

Full list of author information is available at the end of the article
} 


\section{Background}

Adenoid cystic carcinoma is a relatively rare tumor in the parotid gland with a $10 \%$ incidence, compared with a $30 \%$ incidence in the minor salivary glands. Histologically, this tumor shows higher rates of local growth, perineural invasion and distant metastasis. Many cases of delayed recurrence after definite treatment have been reported, indicating the difficulty of treating and controlling this tumor. Factors related to the recurrence and prognosis of adenoid cystic carcinoma include tumor stage, histological classification, status of the resected tumor margin, lymph node metastasis, and perineural invasion [1-3]. Investigations of the molecular markers of this tumor and the development of targeted therapy are currently ongoing. Ki-67, p53, bcl-2, epidermal growth factor receptor (EGFR), human epidermal growth receptor-2 (HER2), proliferating cell nuclear antigen (PCNA), and Runt-related transcription factor-3 (RNUX3) are representative markers of adenoid cystic carcinoma [4-6]. The inhibition of vascular endothelial growth factor (VEGF) has also been reported to reduce local recurrence and distant metastasis [7].

The c-kit protein is a transmembrane receptor with a tyrosine kinase function. The overexpression of c-kit has been reported in various malignant tumors $[8,9]$, including adenoid cystic carcinoma and some salivary gland tumors $[10,11]$. However, there is little information on the prognostic value of c-kit, and the therapeutic efficacy of a tyrosine kinase inhibitor (imatinib) is not well established [12]. EGFR is a transmembrane receptor found in epithelial cancers such as breast, lung, bladder, ovary, prostate, and head and neck cancers $[3,13]$. The overexpression of EGFR in head and neck cancer is associated with an advanced stage, lymph node metastasis, low survival rate, and poor response to radiation therapy $[14,15]$. Although many studies on the role of EGFR in salivary gland tumors have been reported, there is some debate about its prognostic significance [16]. VEGF is a major vascular formative factor in the process of epithelial carcinogenesis and tumor metastasis. It selectively functions in the vascular endothelial tissue and is expressed in various organs such as lung, breast and gastrointestinal organs [17]. The overexpression of VEGF is involved in perineural invasion and recurrence, and it heralds a poor survival rate [18]. In an animal study, the inhibition of VEGF expression reduced growth and distant metastasis of adenoid cystic cancer [19]. Clinical trials with a single inhibitor (imatinib for c-kit; trastuzumab or cetuximab for ErbB1 and ErbB2) have shown low response rates in salivary gland cancer [20]. Intriguingly, concomitant inhibition of EGF and VEGF reduced the growth and metastasis of adenoid cystic carcinoma in an animal model [19]. EGFR overexpression and the absence of c-kit expression are negative prognostic factors in adenoid cystic cancer [21]. Based on these reports, we hypothesized that the elucidation of the diverse changes in these proteins would improve treatment outcomes. In the present study, we evaluated the relationship between c-kit, EGFR, and VEGF expression and the survival or local control rate of adenoid cystic carcinoma.

\section{Methods}

\section{Patients and treatment}

This retrospective study using medical chart reviews was performed after approved by the institutional review board of Asan Medical Center. Written informed consent was obtained from the patients for publication of this report and any accompanying images. We reviewed the medical records of 48 patients who were diagnosed with and treated for salivary adenoid cystic carcinoma from January 1990 to January 2006 at a single institute. The presence of lymph node metastasis was preoperatively evaluated by neck ultrasonography (US), computed tomography (CT), and magnetic resonance imaging (MRI). Tumor locations were divided into the submandibular, parotid, and minor salivary glands. Distant metastasis was identified with $\mathrm{Tc}^{99 \mathrm{~m}}$ bone scanning and $\mathrm{F}^{18}$-flurodeoxyglucose positron emission tomography $\left(\mathrm{F}^{18}\right.$-FDG PET). We investigated tumor size, the histological pattern, the presence of perineural invasion, invasion of surgical margins, and lymph node metastasis according to the pathology reports. The histological patterns were classified as tubular, cribriform, and solid types on the basis of the WHO classification (2005). Marginal involvement included microscopic and macroscopic invasion of the margin of the specimen. When lymph node metastasis was confirmed on preoperative fine needle aspiration cytology with or without US, therapeutic neck dissection from level I to V was performed. Selective neck dissection, including levels I to III, was performed in cases of clinical T3, T4 or suspicious findings on radiology. Lymph node metastasis was defined when confirmed histologically after surgery. A close resection margin ( $<1 \mathrm{~cm}$ from the tumor), an unclear margin, a perineural invasion, and an advanced stage (III, IV) were indications for adjuvant radiation therapy. We also checked for local recurrence, distant metastasis, and survival after treatment $[22,23]$. The observation period was defined from the end point of treatment to the most recent follow-up date.

\section{Tissue microarray blocks}

Two tissue microarray blocks were made from the formalin-fixed, paraffin-embedded tissue of the 48 patients with adenoid cystic carcinoma. Each slide was reviewed under a microscope, and representative areas were selected for immunohistochemistry. These were marked 
on the slides stained with hematoxylin and eosin, and their corresponding areas on each block were punched using a tissue cylinder with a $0.6 \mathrm{~mm}$ diameter. These cores were transferred to the recipient blocks using a tissue-arraying instrument (Beecher Instruments, Silver Spring, MD, USA). Considering the heterogeneity of the tumor, the samples were arrayed in duplicate to avoid tissue loss.

\section{Immunohistochemistry}

Immunohistochemical staining for c-kit, EGFR, and VEGF was performed using a Benchmark automatic immunostaining device (Ventana Medical Systems, Tucson, AZ, USA). Tissue sections ( $4 \mu \mathrm{m}$ thick) were deparaffinized in $10 \%$ xylene, dehydrated in $100 \%, 95 \%$, and $75 \%$ ethanol solutions, and washed with distilled water. For antigen retrieval, the sections were immersed in $10 \mathrm{mM}$ citrate buffer ( $\mathrm{pH} \mathrm{6.0)}$ and microwaved for 10 min. Endogenous peroxidases activities and nonspecific antigens were eliminated with $3 \%$ hydrogen peroxide in methanol and AB blocker (Roche, Basel, Switzerland). The sections were incubated with primary antibodies against c-kit (CD117, 1:400 dilution; DAKO, Glostrup, Denmark), EGFR (1:500 dilution; DAKO), and VEGF (1:100 dilution; Zymed, South San Francisco, CA, USA). Immunodetection was performed with biotinylated antimouse immunoglobulin followed by peroxidase-labeled streptavidin, using a labeled streptavidin-biotin kit (DAKO). As a chromogen, 3,3'-diaminobenzidine was used, and the sections were counterstained with Harris hematoxylin. The intensity of the immunohistochemical staining of c-kit (membranous/cytoplasmic), EGFR (membranous), and VEGF (cytoplasmic) was semiquantitatively scored as 0 (reactivity in $<5 \%$ of the tumor cells), $1+$ (reactivity $5 \%-1 / 3$ of the tumor cells), $2+$ (reactivity in $1 / 3$ to $2 / 3$ of the tumor cells), or $3+$ (reactivity $>2 / 3$ of the tumor cells). Cases with scores of $2+$ and $3+$ were regarded as positive.

\section{Statistical analysis}

SPSS software (version 14.0; SPSS Inc., Chicago, IL, USA) was used for the statistical analysis. To identify relationships between clinical factors and immunostaining of markers, Fisher's exact test was used for categorical data and the Mann-Whitney $U$ test was used for continuous variables. Univariate and multivariate analyses using Cox's proportional hazard model were performed with a backward, stepwise elimination approach. At each step, the least significant factor with $P>0.10$ was eliminated, and each remaining factor in the model was reassessed. The limit for including factors was set at $20 \%$. To simplify binary logistic regression analyses, we divided the data into two groups based on immunoreactivity. The Kaplan-Meier method was used to analyze survival rates. Values of $P$ below 0.05 indicated statistical significance.

\section{Results}

\section{Study population}

Forty-eight patients (19 males and 29 females) with adenoid cystic cancer in the salivary gland were enrolled. The average patient age was 49.7 years $( \pm 21.9)$. The numbers of tumors that involved the submandibular gland, parotid gland, or minor salivary gland were $12(25 \%), 18(38 \%)$, and $18(38 \%)$, respectively. The average tumor size was 2.6 $\mathrm{cm}( \pm 2.2)$. Twenty-seven cases were classified into three groups (tubular, two cases (4\%); cribriform, 18 cases (38\%); solid, seven cases (15\%)) according to the histology, and 21 cases $(44 \%)$ had no records or had unclear tumor types. Perineural invasion and cervical lymph node metastasis were identified in $22(56 \%)$ and six $(13 \%)$ cases, respectively. Twelve patients underwent PET, and the average standard uptake value in the primary lesion was $3.0( \pm 2.1)$. Ten patients (21\%) underwent only surgical management, while $32(67 \%)$ received adjuvant radiation therapy after surgery. Concurrent chemoradiation therapy following surgery was administered in six cases (14\%) (Table 1).

\section{Table 1 Characteristics of patients and tumors}

\begin{tabular}{|c|c|c|}
\hline Characteristics & Category & Number of patients (\%) \\
\hline \multirow[t]{2}{*}{ Sex } & Male & $19(40)$ \\
\hline & Female & $29(60)$ \\
\hline \multirow[t]{3}{*}{ Site } & Submandibular & $12(25)$ \\
\hline & Parotid & $18(38)$ \\
\hline & Minor & $18(38)$ \\
\hline \multirow[t]{4}{*}{ Histology } & Tubular & $2(4)$ \\
\hline & Cribriform & $18(38)$ \\
\hline & Solid & $7(15)$ \\
\hline & Indeterminate & $21(44)$ \\
\hline \multirow[t]{2}{*}{ Perineural invasion } & Negative & $26(54)$ \\
\hline & Positive & $22(46)$ \\
\hline \multirow[t]{2}{*}{ Resection margin } & Negative & $21(44)$ \\
\hline & Positive & $27(56)$ \\
\hline \multirow[t]{2}{*}{ Lymph node involvement } & Negative & $42(88)$ \\
\hline & Positive & $6(13)$ \\
\hline \multirow[t]{4}{*}{ Treatment } & Surgery only & $10(21)$ \\
\hline & Surgery + RT & $32(67)$ \\
\hline & Surgery + CCRT & $6(13)$ \\
\hline & & Mean $( \pm S D)$ \\
\hline Age (years) & & $49.7( \pm 14.2)$ \\
\hline Tumor size $(\mathrm{cm})$ & & $2.5( \pm 1.2)$ \\
\hline PET (SUV) & & $3.0( \pm 1.2)$ \\
\hline
\end{tabular}

CCRT, concurrent chemoradiation therapy; PET, positron emission tomography; RT, radiation therapy; SUV, standard uptake value. 


\section{Immunohistological staining}

Forty-five cases (94\%) showed c-kit immunoreactivity, with 23 weakly positive, 19 moderately positive, and three strongly positive cases. For EGFR, 27 cases (56\%) were positive, comprising 19 weakly positive and eight moderately positive cases; no strongly positive cases were observed. Forty-two cases (88\%) showed positive immunoreactivity for VEGF: 12 were weakly positive, 17 were moderately positive, and 13 were strongly positive (Figure 1). The patients were divided into two groups, a negative or weakly positive group and a more-thanmoderately positive group, according to the staining intensity for c-kit and VEGF. For EGFR, patients were divided into negative and positive groups. There was no significant correlation between the staining intensity for each marker (c-kit and EGFR, $P=0.422$; EGFR and VEGF, $P=0.499$; VEGF and c-kit, $P=0.454)$. VEGF showed stronger expression in the parotid gland $(P=0.032)$ than in the other sites, and marginal invasion was frequent in cases with high VEGF expression $(P=0.02)$. The other makers showed no notable trends (Table 2).

\section{Recurrence after treatment}

The mean follow-up period was 70.9 months (range, 4.0 to 159.1 months). There were 19 patients (39.6\%) with recurrence, and the average time until detection of recurrence was 24.9 months (range, 2.0 to 97.6 months). Four cases showed local recurrence, 10 showed distant metastasis (lung, nine cases; multiple, one case), and five showed both local and distant metastasis. Lymph node metastasis was closely related to recurrence after the initial treatment $(P<0.001)$. However, recurrence was not associated with the staining intensity of c-kit $(P=0.987)$, EGFR $(P=0.747)$, or VEGF $(P=0.927)$ (Table 3$)$.

\section{Survival rate}

Eleven patients died of the disease, and the mean survival period was 38.0 months (range, 4.4 to 144.2 months). The five-year survival rate was $88.2 \%$, and the complete remission rate was $72.9 \%$. No marker staining intensity was associated with a difference in survival rate based on the Kaplan-Meier survival curve, whereas lymph node metastasis was significantly related to survival rate (Figure 2). Using Cox's proportional hazard model, we analyzed the factors that might have influenced the survival rate, and only lymph node metastasis showed a close relationship to the survival rate $(P=0.049)$. The expression of $\mathrm{c}$-kit $(P=0.864)$, EGFR $(P=0.716)$, and VEGF $(P=0.198)$ did not show a close relationship with the survival rate (Table 4$)$.
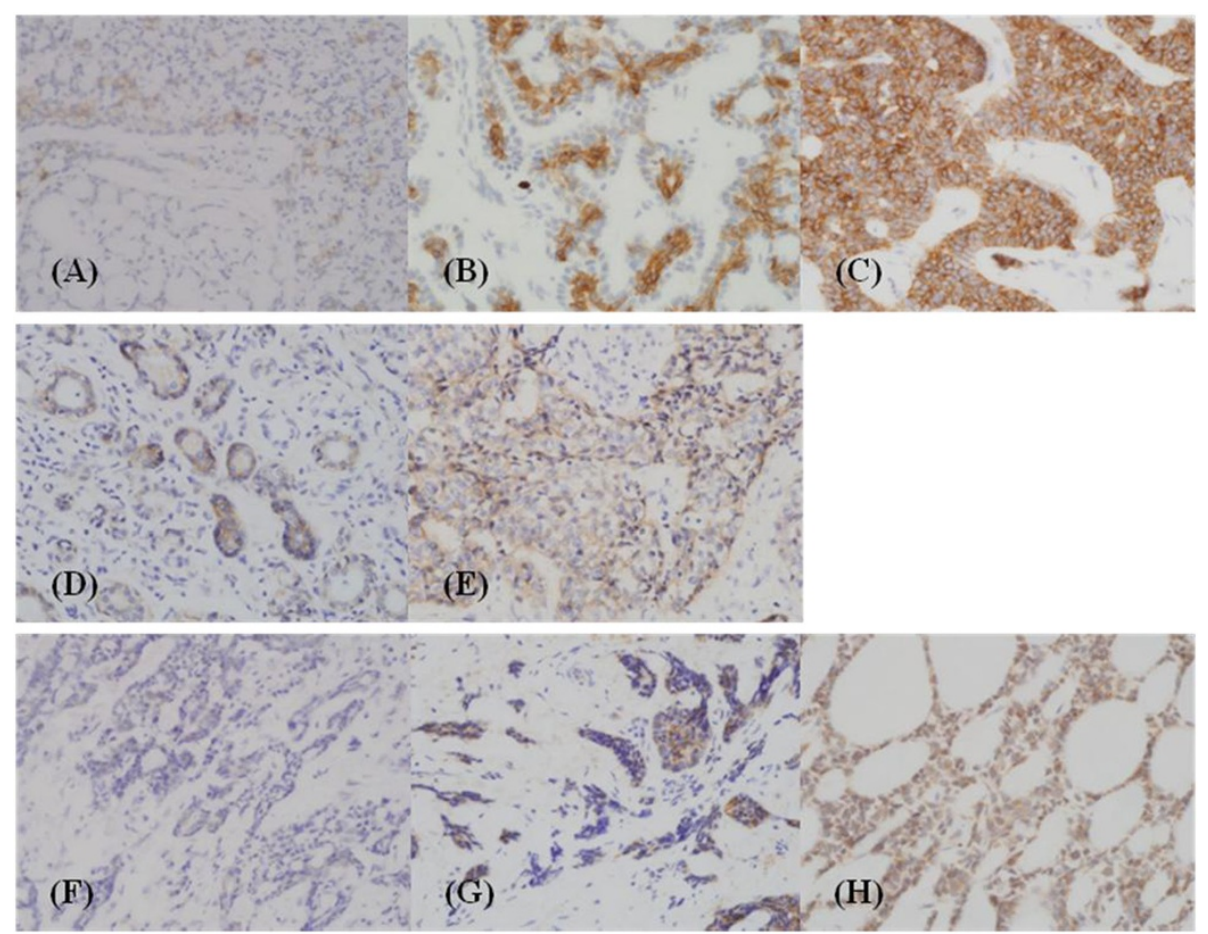

Figure 1 Immunohistochemical staining of adenoid cystic carcinomas of the salivary gland. C-kit (CD 117) expression of weakly (1+, A), moderately $(2+, \mathbf{B})$, and strongly positive $(3+, \mathbf{C})$ cases; EGFR (epidermal growth factor receptor) expression of weakly (D) and moderately positive (E) cases; VEGF (vascular endothelial growth factor) expression of weakly (F), moderately (G), and strongly positive $\mathbf{( H )}$ cases. Expressions of c-kit (membranous/cytoplasmic), EGFR (membranous), and VEGF (cytoplasmic) were scored as follows: 0 , reactivity in $<5 \%$ of tumor cells; $1+$, reactivity in $5 \%-1 / 3$ of tumor cells; $2+$, reactivity in $1 / 3$ to $2 / 3$ of tumor cells; $3+$, reactivity $>2 / 3$ of tumor cells. 
Table 2 Correlation between expression of tumor markers and clinical factors

\begin{tabular}{|c|c|c|c|c|c|c|c|c|c|c|}
\hline \multirow[b]{2}{*}{ Clinical factor } & & \multicolumn{3}{|l|}{ c-kit } & \multicolumn{3}{|c|}{ EGFR } & \multicolumn{3}{|l|}{ VEGF } \\
\hline & & $0,1+$ & $2+, 3+$ & $P$ & 0 & $1+, 2+$ & $P$ & $0,1+$ & $2+, 3+$ & $P$ \\
\hline \multirow[t]{2}{*}{ Sex } & Male & 12 & 7 & 0.312 & 9 & 10 & 0.683 & 6 & 13 & 0.493 \\
\hline & Female & 14 & 5 & & 12 & 17 & & 12 & 17 & \\
\hline \multirow[t]{3}{*}{ Site } & Submandibular gland & 5 & 7 & 0.149 & 6 & 6 & 0.53 & 1 & 11 & 0.032 \\
\hline & Parotid gland & 8 & 10 & & 6 & 12 & & 7 & 11 & \\
\hline & Minor salivary gland & 13 & 5 & & 9 & 9 & & 10 & 8 & \\
\hline \multirow[t]{4}{*}{ Histology } & Tubular & 1 & 1 & 0.961 & 0 & 2 & 0.633 & 0 & 2 & 0.8 \\
\hline & Cribriform & 9 & 9 & & 7 & 11 & & 7 & 11 & \\
\hline & Solid & 4 & 3 & & 4 & 3 & & 2 & 5 & \\
\hline & Indeterminate & 12 & 9 & & 10 & 11 & & 9 & 12 & \\
\hline \multirow[t]{2}{*}{ Perineural invasion } & Negative & 15 & 11 & 0.594 & 12 & 14 & 0.715 & 8 & 18 & 0.295 \\
\hline & Positive & 11 & 11 & & 9 & 13 & & 10 & 12 & \\
\hline \multirow[t]{2}{*}{ Resection margin } & Negative & 13 & 8 & 0.343 & 7 & 14 & 0.199 & 11 & 10 & 0.02 \\
\hline & Positive & 13 & 14 & & 14 & 13 & & 7 & 20 & \\
\hline \multirow[t]{2}{*}{ Lymph node involvement } & Negative & 24 & 18 & 0.392 & 17 & 4 & 0.383 & 16 & 26 & 1 \\
\hline & Positive & 2 & 4 & & 25 & 2 & & 2 & 4 & \\
\hline
\end{tabular}

EGFR, epidermal growth factor receptor; VEGF, vascular endothelial growth factor.

Table 3 Effect of tumor markers and clinical factors on tumor recurrence

\begin{tabular}{|c|c|c|c|c|}
\hline Marker/factor & & HR & $95 \% \mathrm{Cl}$ & $P$ \\
\hline \multirow[t]{2}{*}{ c-kit } & $0,1+$ & 1 & $0.402-2.45$ & 0.987 \\
\hline & $2+, 3+$ & 0.993 & & \\
\hline \multirow[t]{2}{*}{ EGFR } & 0 & 0.862 & $0.349-2.129$ & 0.747 \\
\hline & $1+, 2+$ & 1 & & \\
\hline \multirow[t]{2}{*}{ VEGF } & $0,1+$ & 0.958 & $0.386-2.377$ & 0.927 \\
\hline & $2+, 3+$ & 1 & & \\
\hline \multirow[t]{2}{*}{ Sex } & Male & 1 & $0.195-1.212$ & 0.122 \\
\hline & Female & 0.486 & & \\
\hline \multirow[t]{3}{*}{ Site } & Submandibular gland & 1 & & \\
\hline & Parotid gland & 0.392 & $0.18-1.45$ & 0.153 \\
\hline & Minor salivary gland & 0.81 & $0.266-2.468$ & 0.71 \\
\hline \multirow[t]{4}{*}{ Histology } & Tubular & 1 & & \\
\hline & Cribriform & 0.513 & $0.061-4.283$ & 0.538 \\
\hline & Solid & 3.727 & $0.423-32.813$ & 0.236 \\
\hline & Indeterminate & 0.446 & $0.053-3.781$ & 0.459 \\
\hline \multirow[t]{2}{*}{ Perineural invasion } & Negative & 1 & $0.384-2.405$ & 0.932 \\
\hline & Positive & 0.961 & & \\
\hline \multirow[t]{2}{*}{ Resection margin } & Negative & 1 & $0.224-1.406$ & 0.217 \\
\hline & Positive & 0.561 & & \\
\hline \multirow[t]{2}{*}{ Lymph node involvement } & Negative & 1 & $2.178-19.982$ & $<0.001$ \\
\hline & Positive & 6.597 & & \\
\hline \multirow[t]{3}{*}{ Treatment } & Surgery only & 1 & & \\
\hline & Surgery + RT & 0.89 & $0.192-4.122$ & 0.881 \\
\hline & Surgery + CCRT & 4.002 & $0.793-20.197$ & 0.093 \\
\hline Age (years) & & 0.949 & $0.902-0.998$ & 0.071 \\
\hline Tumor size $(\mathrm{cm})$ & & 0.864 & $0.566-1.318$ & 0.498 \\
\hline
\end{tabular}

CCRT, concurrent chemoradiation therapy; Cl, confidence interval; EGFR, epidermal growth factor receptor; $\mathrm{HR}$, hazard ratio; RT, radiation therapy; VEGF, vascular endothelial growth factor. 
(A)

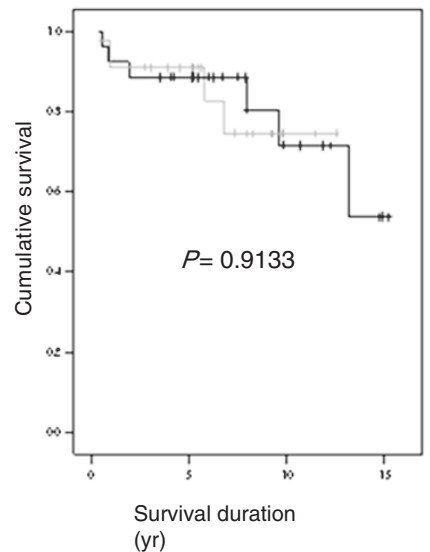

(C)
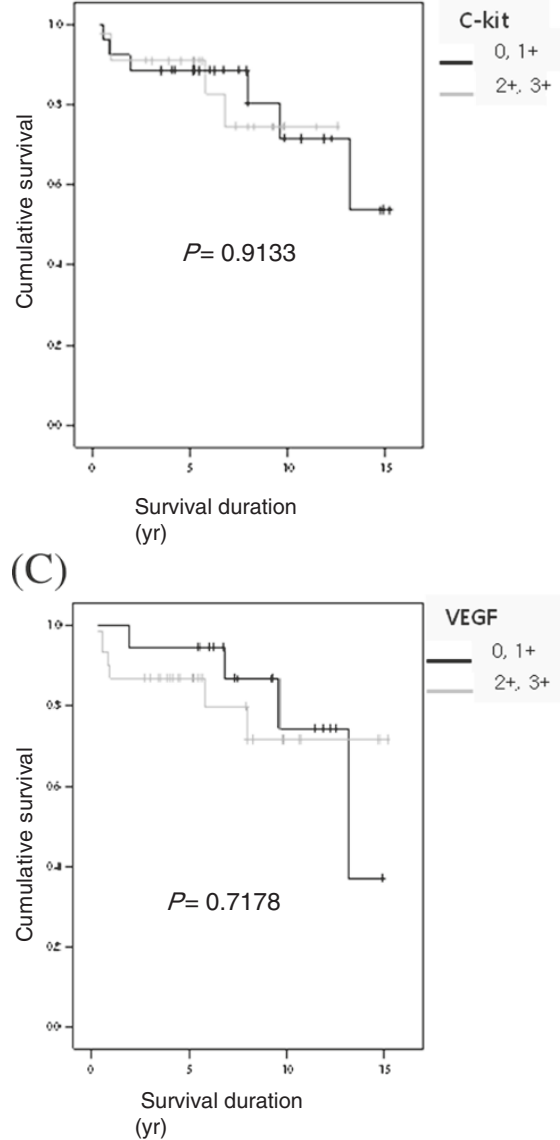

(B)

(D)

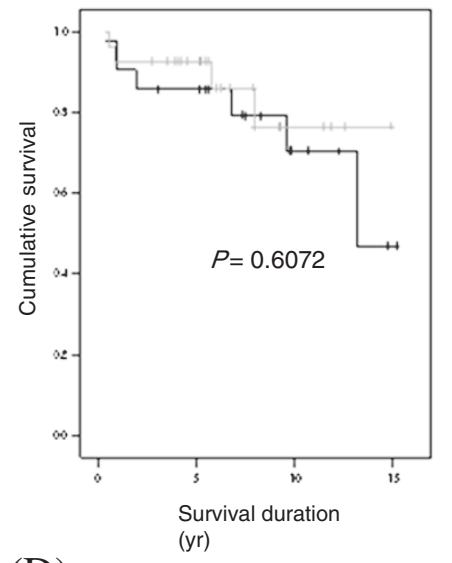

EGFR

$-1+, 2+$

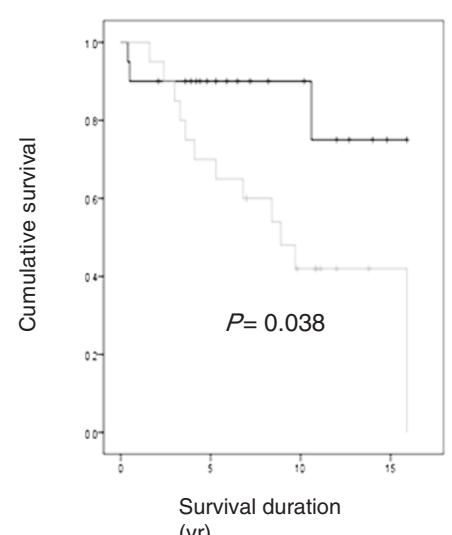

(yr)

Figure 2 Overall survival curves of the patients according to (A) c-kit, (B) epidermal growth factor receptor (EGFR), (C) vascular endothelial growth factor (VEGF) expression, and (D) lymph node metastasis. Survival curves were calculated using the Kaplan-Meier method and analyzed by the log-rank test.

\section{Discussion}

The low response rate of adenoid cystic cancer to tyrosine kinase inhibitors and EGFR inhibitors indicates that no single molecule is dominant in tumor invasion and spread of this cancer [19-21,24]. The class III receptor tyrosine kinase and c-kit is important for normal hematopoiesis, melanin production and reproductive cell production. Imatinib mesylate (Gleevec ${ }^{\mathrm{Tm}}$ ), a tyrosine kinase inhibitor, is very effective in treating chronic myeloid leukemia and show good efficacy for the treatment of advanced gastrointestinal tumors with positive c-kit expression [24]. The expression of c-kit in salivary adenoid cystic cancer has been variably reported as $78 \%$ to $100 \%$. The high c-kit expression in adenoid cystic cancer suggests that this cancer may respond to treatment with imatinib mesylate, although studies with imatinib have not shown consistent results [12,25]. The relationship between c-kit expression and prognosis has been controversial, although the expression of c-kit was stronger in the tubular or cribriform type than in the solid type
$[21,26]$. The discrepancy might have been caused by differences in staining techniques and the lack of a standard method for evaluating staining intensity. In the present investigation, 94\% of the tumors expressed c-kit, but no significant relationship with other clinical variables or prognosis was identified.

EGF is found in the primary duct and terminal buds, and its distribution and density decrease with aging [27]. EGFR is present in salivary gland tumors, with expression reported in $0 \%$ to $85 \%$ of adenoid cystic cancers [27]. In the present study, $56 \%$ of the tumors were positive for EGFR. The overexpression of EGFR is reportedly related to a poor prognosis in salivary gland cancer [21], which is different from our results. VEGF promotes vascular proliferation in tumors from peripheral tissue and enhances vessel permeability with a selective effect on vascular endothelial cells. VEGF expression is found in various tumors, such as those of esophageal cancer, small cell lung cancer, thyroid cancer, breast cancer, and cervical cancer [28], as well as head and neck cancer. VEGF expression is 
Table 4 Effect of tumor markers and clinical factors on survival

\begin{tabular}{|c|c|c|c|c|}
\hline Marker/factor & & HR & $95 \% \mathrm{Cl}$ & $P$ \\
\hline \multirow[t]{2}{*}{ c-kit } & $0,1+$ & 1 & $0.297-4.251$ & 0.864 \\
\hline & $2+, 3+$ & 1.124 & & \\
\hline \multirow[t]{2}{*}{ EGFR } & 0 & 1 & $0.206-2.957$ & 0.716 \\
\hline & $1+, 2+$ & 0.781 & & \\
\hline \multirow[t]{2}{*}{ VEGF } & $0,1+$ & 1 & $0.624-11.392$ & 0.198 \\
\hline & $2+, 3+$ & 2.623 & & \\
\hline \multirow[t]{2}{*}{ Sex } & Male & 1 & $0.01-0.639$ & 0.17 \\
\hline & Female & 0.8 & & \\
\hline \multirow[t]{3}{*}{ Site } & Submandibular gland & 1 & & \\
\hline & Parotid gland & 0 & & 0.995 \\
\hline & Minor salivary gland & 0.33 & $0.07-1.563$ & 0.162 \\
\hline \multirow[t]{2}{*}{ Perineural invasion } & Negative & 1 & $0.491-\sim 7.02$ & 0.362 \\
\hline & Positive & 1.856 & & \\
\hline \multirow[t]{2}{*}{ Resection margin } & Negative & 1 & $0.173-2.505$ & 0.54 \\
\hline & Positive & 0.659 & & \\
\hline \multirow[t]{2}{*}{ Lymph node involvement } & Negative & 1 & $0.791-14.06$ & 0.049 \\
\hline & Positive & 4.362 & & \\
\hline \multirow[t]{3}{*}{ Treatment } & Surgery only & 1 & & \\
\hline & Surgery + RT & 0.224 & $0.033-1.508$ & 0.124 \\
\hline & Surgery + CCRT & 0.831 & $0.113-6.127$ & 0.856 \\
\hline \multirow[t]{2}{*}{ Age (year) } & $<45$ & 1 & & \\
\hline & $\geq 45$ & 1.078 & $1.016 \sim 1.143$ & 0.103 \\
\hline \multirow[t]{2}{*}{ Tumor size $(\mathrm{cm})$} & $\leq 2$ & 1 & & \\
\hline & $>2$ & 0.838 & $0.452 \sim 1.554$ & 0.575 \\
\hline
\end{tabular}

CCRT, concurrent chemoradiation therapy; Cl, confidence interval; EGFR, epidermal growth factor receptor; $\mathrm{HR}$, hazard ratio; RT, radiation therapy; VEGF, vascular endothelial growth factor.

associated with cervical lymph node metastasis, higher cancer stage, perineural invasion, recurrence, and low survival $[18,28]$. Higher VEGF expression was found in solid tumors compared with tubular or cribriform types, and the survival rate decreased with higher VEGF expression [29]. In the present study, there was no relationship between high VEGF expression and lymph node metastasis, recurrence, or survival, contrary to our expectations. This was possibly, attributable to the subjective assessment of the differences in immunostaining and the semiquantitative analysis. A few investigations on treatments targeting VEGF in salivary gland cancer have shown partial remission, suggesting the targeting of VEGF for the management of adenoid cystic cancer [30]. Negative results regarding the prognostic usefulness of molecular markers in the present study might have been due to the threshold criteria used for positive EGFR, c-kit, and VEGF on immunoreactivity [21]. The availability of normal tissue as a negative control would have helped in scoring positive immunochemical staining.

Histological differentiation in adenoid cystic cancer is variable and reflects its malignant potential [31]. Indeterminate cases comprised $44 \%$ of all cases in the present study, and most of these were mixed type with no predominant type. This result was attributable to a lack of detailed pathologic reports on subtypes, which is a limitation of the present retrospective study. In addition, tumor size and involved sites were not recorded definitively enough to be analyzed. Lymph node metastasis alone was significantly associated with the prognosis. Previous studies have reported that perineural invasion had strong relationships to distant metastasis and the survival rate $[32,33]$. These relationships were not significant in the present investigation because of the small number of cases. In earlier studies, cervical lymph node metastasis was present in $20 \%$ of adenoid cystic cancers and was related to a high recurrence rate and low survival rate $[34,35]$. A similar pattern of metastasis was observed in the present study. Distant metastasis was observed in 10 cases, with the lung being the most frequently involved single site $(n=9)$. Multiple sites (lung, bone, and brain) were involved in one case.

Recurrence of adenoid cystic cancer has been found usually within 56 months. Death occurred within three years after the detection of distant metastasis in 54\%, whereas survival in excess of 10 years was recorded in 
$10 \%$ of the patients [36,37]. Considering that late recurrence is characteristic of adenoid cystic cancer, the analysis of recurrence during a short follow-up period is another limitation of the present study.

Lymph node metastasis is a key step in the development of metastasis and is a determining factor of prognosis. Traditionally, it has been thought that tumors spread to lymph nodes by direct extension in an orderly, defined manner based on mechanical considerations and transverse lymphatics [38]. However, lymph node metastasis cannot explain local recurrence, distant metastasis, or poor treatment outcomes. Based on clinical and laboratory research, Fisher has proposed that biological, rather than anatomical, factors may be responsible for the appearance of metastasis in certain nodes and the lack of metastasis in others, suggesting that cancer is not a local disease, but a systemic disease [39]. Oligometastasis implies a critical interaction between systemically disseminated cancer cells and the host; this concept leads to the notion that confined distant metastasis could be completely cured by local therapy in some cases [40]. Based on these ideas, we believe that lymph node metastasis is both a key step and coincident finding. Thus, an analysis of markers specific for lymph node metastasis may be useful for stratifying prognosis.

Anticancer radiation therapy for head and neck cancer can reduce local recurrence, but not distant metastasis $[23,41]$. The molecular markers used in the present study are related to the prognosis of other head and neck malignancies, including salivary gland tumors. Although we did not identify the prognostic significance of these molecular markers, immunohistochemical staining revealed high expression levels of c-kit, EGFR and VEGF in the present study. These findings indicate a need for further research on these markers in adenoid cystic cancer.

\section{Conclusions}

Lymph node metastasis was the only factor that was related to recurrence and survival rate following treatment of salivary adenoid cystic cancer. Despite the high expression levels of c-kit, EGFR, and VEGF, these markers were not significantly correlated with recurrence and the prognosis of adenoid cystic cancer. However, the expression levels of c-kit, EGFR, and VEGF exhibited variable changes, suggesting that interrelationships among these proteins may provide approaches for molecularly targeted therapy for salivary adenoid cystic cancer.

\section{Competing interests}

All authors have no competing interests.

\section{Authors' contributions}

SKL, MSK, and SYN participated in the design of the study, carried out the extraction and analysis of data, and wrote the manuscript. KJC reviewed pathology of the enrolled slides. YSL and SYN performed the critical review of the literature. KJC and SYK assisted in the collection of the clinical data and in reviewing the manuscript. SYN assisted in reviewing the manuscript. All authors have read and approved the final manuscript.

\section{Author details}

'Department of Otolaryngology, Kangwon National University, College of Medicine, 192-1 Hyoza 2-Dong, Chuncheon, Kangwon 200-701, South Korea. 2Department of Otolaryngology, Asan Medical Center, University of Ulsan, College of Medicine, 388-1 Pungnap-2dong, Songpa-gu, Seoul 138-736, South Korea. ${ }^{3}$ Department of Otorhinolaryngology-Head and Neck Surgery, Research Institute for Convergence of Biomedical Science and Technology, Pusan National University Yangsan Hospital, Beomeo-ri, Mulgeum-eup, Yangsan, Gyeongsangnam-do 626-770, Republic of Korea. ${ }^{4}$ Department of Pathology, Asan Medical Center, University of Ulsan, College of Medicine, 388-1 Pungnap-2dong, Songpa-gu, Seoul 138-736, South Korea.

Received: 26 June 2012 Accepted: 24 November 2012 Published: 11 December 2012

\section{References}

1. Chen AM, Bucci MK, Weinberg V, Garcia J, Quivey JM, Schechter NR, Phillips TL, Fu KK, Eisele DW: Adenoid cystic carcinoma of the head and neck treated by surgery with or without postoperative radiation therapy: prognostic features of recurrence. Int J Radiat Oncol Biol Phys 2006, 66:152-159.

2. Garden AS, Weber RS, Morrison WH, Ang KK, Peters LJ: The influence of positive margins and nerve invasion in adenoid cystic carcinoma of the head and neck treated with surgery and radiation. Int I Radiat Oncol Biol Phys 1995, 32:619-626

3. Mendenhall WM, Morris CG, Amdur RJ, Werning JW, Hinerman RW, Villaret DB: Radiotherapy alone or combined with surgery for adenoid cystic carcinoma of the head and neck. Head Neck 2004, 26:154-162.

4. Dodd RL, Slevin NJ: Salivary gland adenoid cystic carcinoma: a review of chemotherapy and molecular therapies. Oral Oncol 2006, 42:759-769.

5. Elkin AD, Jacobs CD: Tamoxifen for salivary gland adenoid cystic carcinoma: report of two cases. J Cancer Res Clin Oncol 2008, 134:1151-1153.

6. He JF, Ge MH, Zhu X, Chen C, Tan Z, Li YN, Gu ZY: Expression of RUNX3 in salivary adenoid cystic carcinoma: implications for tumor progression and prognosis. Cancer Sci 2008, 99:1334-1340.

7. Zhang J, Peng B, Chen X: Expressions of nuclear factor kappaB, inducible nitric oxide synthase, and vascular endothelial growth factor in adenoid cystic carcinoma of salivary glands: correlations with the angiogenesis and clinical outcome. Clin Cancer Res 2005, 11:7334-7343.

8. DiPaola RS, Kuczynski WI, Onodera K, Ratajczak MZ, Hijiya N, Moore J, Gewirtz AM: Evidence for a functional kit receptor in melanoma, breast, and lung carcinoma cells. Cancer gene therapy 1997, 4:176-182.

9. Hirota S, Isozaki K, Moriyama Y, Hashimoto K, Nishida T, Ishiguro S, Kawano K, Hanada M, Kurata A, Takeda M, Muhammad Tunio G, Matsuzawa Y, Kanakura Y, Shinomura Y, Kitamura Y: Gain-of-function mutations of c-kit in human gastrointestinal stromal tumors. Science 1998, 279:577-580.

10. Jeng YM, Lin CY, Hsu HC: Expression of the c-kit protein is associated with certain subtypes of salivary gland carcinoma. Cancer Lett 2000, 154:107-111.

11. Locati LD, Perrone F, Losa M, Mela M, Casieri P, Orsenigo M, Cortelazzi B, Negri T, Tamborini E, Quattrone P, Bossi P, Rinaldi G, Bergamini C, Calderone RG, Liberatoscioli C, Licitra L: Treatment relevant target immunophenotyping of 139 salivary gland carcinomas (SGCs). Oral Oncol 2009, 45:986-990.

12. Hotte SJ, Winquist EW, Lamont E, MacKenzie M, Vokes E, Chen EX, Brown S, Pond GR, Murgo A, Siu LL: Imatinib mesylate in patients with adenoid cystic cancers of the salivary glands expressing c-kit: a Princess Margaret Hospital phase II consortium study. J Clin Oncol 2005, 23:585-590.

13. Dassonville O, Formento JL, Francoual M, Ramaioli A, Santini J, Schneider M, Demard F, Milano G: Expression of epidermal growth factor receptor and survival in upper aerodigestive tract cancer. J Clin Oncol 1993, 11:1873-1878.

14. Gupta AK, McKenna WG, Weber CN, Feldman MD, Goldsmith JD, Mick R, Machtay M, Rosenthal DI, Bakanauskas VJ, Cerniglia GJ, Bernhard EJ, Weber RS, Muschel RJ: Local recurrence in head and neck cancer: relationship to radiation resistance and signal transduction. Clin Cancer Res 2002, 8:885-892. 
15. Xia W, Lau YK, Zhang HZ, Xiao FY, Johnston DA, Liu AR, Li L, Katz RL, Hung MC: Combination of EGFR, HER-2/neu, and HER-3 is a stronger predictor for the outcome of oral squamous cell carcinoma than any individual family members. Clin Cancer Res 1999, 5:4164-4174.

16. Sorensen KB, Godballe C, de Stricker K, Krogdahl A: Parotid carcinoma: expression of kit protein and epidermal growth factor receptor. J Oral Pathol Med 2006, 35:286-291.

17. Dvorak HF, Brown LF, Detmar M, Dvorak AM: Vascular permeability factor/ vascular endothelial growth factor, microvascular hyperpermeability, and angiogenesis. Am J Pathol 1995, 146:1029-1039.

18. Lim JJ, Kang S, Lee MR, Pai HK, Yoon HJ, Lee Jl, Hong SP, Lim CY: Expression of vascular endothelial growth factor in salivary gland carcinomas and its relation to p53, Ki-67 and prognosis. J Oral Pathol Med 2003, 32:552-561.

19. Younes MN, Park YW, Yazici YD, Gu M, Santillan AA, Nong X, Kim S, Jasser $\mathrm{SA}$, El-Naggar AK, Myers JN: Concomitant inhibition of epidermal growth factor and vascular endothelial growth factor receptor tyrosine kinases reduces growth and metastasis of human salivary adenoid cystic carcinoma in an orthotopic nude mouse model. Mol Cancer Ther 2006, 5:2696-2705.

20. Milano A, Longo F, Basile M, laffaioli RV, Caponigro F: Recent advances in the treatment of salivary gland cancers: emphasis on molecular targeted therapy. Oral Oncol 2007, 43:729-734.

21. Ettl T, Schwarz S, Kleinsasser N, Hartmann A, Reichert TE, Driemel O: Overexpression of EGFR and absence of C-KIT expression correlate with poor prognosis in salivary gland carcinomas. Histopathology 2008, 53:567-577.

22. Beckhardt RN, Weber RS, Zane R, Garden AS, Wolf P, Carrillo R, Luna MA: Minor salivary gland tumors of the palate: clinical and pathologic correlates of outcome. Laryngoscope 1995, 105:1155-1160.

23. Spiro RH: Management of malignant tumors of the salivary glands. Oncology (Williston Park) 1998, 12:671-680. discussion 683.

24. Blanke CD, Rankin C, Demetri GD, Ryan CW, von Mehren M, Benjamin RS, Raymond AK, Bramwell VH, Baker LH, Maki RG, Tanaka M, Hecht JR, Heinrich MC, Fletcher CD, Crowley JJ, Borden EC: Phase III randomized, intergroup trial assessing imatinib mesylate at two dose levels in patients with unresectable or metastatic gastrointestinal stromal tumors expressing the kit receptor tyrosine kinase: S0033. J Clin Oncol 2008, 26:626-632.

25. Alcedo JC, Fabrega JM, Arosemena JR, Urrutia A: Imatinib mesylate as treatment for adenoid cystic carcinoma of the salivary glands: report of two successfully treated cases. Head Neck 2004, 26:829-831.

26. Freier $K$, Flechtenmacher $C$, Walch A, Devens F, Muhling J, Lichter $P$, Joos $S$, Hofele C: Differential KIT expression in histological subtypes of adenoid cystic carcinoma (ACC) of the salivary gland. Oral Oncol 2005, 41:934-939.

27. Tsukitani K, Tatemoto Y, Noda Y, Mori M, Hayashi T, Kato K: Immunohistochemical detection of human epidermal growth factor in submandibular glands and their tumors using a polyclonal antiserum and a monoclonal antibody. Histochemistry 1987, 87:293-300.

28. Warburton G, Nikitakis NG, Roberson P, Marinos NJ, Wu T, Sauk Jנ, Jr, Ord RA, Wahl SM: Histopathological and lymphangiogenic parameters in relation to lymph node metastasis in early stage oral squamous cell carcinoma. J Oral Maxillofac Surg 2007, 65:475-484

29. Zhang $H$, Su SW, Zheng $Y$, Wang L, Ma XD: Expression of nuclear factorkappa B mRNA, inducible nitric oxide synthase and interleukin- 6 in nasal polyp and its role. Zhonghua Er Bi Yan Hou Ke Za Zhi 2003, 38:455-458.

30. Rugo HS, Herbst RS, Liu G, Park JW, Kies MS, Steinfeldt HM, Pithavala YK, Reich SD, Freddo JL, Wilding G: Phase I trial of the oral antiangiogenesis agent AG-013736 in patients with advanced solid tumors: pharmacokinetic and clinical results. J Clin Oncol 2005, 23:5474-5483.

31. Kokemueller H, Eckardt A, Brachvogel P, Hausamen JE: Adenoid cystic carcinoma of the head and neck-a 20 years experience. Int J Oral Maxillofac Surg 2004, 33:25-31.

32. Agarwal JP, Jain S, Gupta T, Tiwari M, Laskar SG, Dinshaw KA, Chaturvedi P, D'Cruz AK, Shrivastava SK: Intraoral adenoid cystic carcinoma: prognostic factors and outcome. Oral Oncol 2008, 44:986-993.

33. Rapidis AD, Givalos N, Gakiopoulou H, Faratzis G, Stavrianos SD, Vilos GA Douzinas EE, Patsouris E: Adenoid cystic carcinoma of the head and neck. Clinicopathological analysis of 23 patients and review of the literature. Oral Oncol 2005, 41:328-335.
34. Le QT, Birdwell S, Terris DJ, Gabalski EC, Varghese A, Fee W Jr, Goffinet DR: Postoperative irradiation of minor salivary gland malignancies of the head and neck. Radiother Oncol 1999, 52:165-171.

35. Spiro RH, Huvos AG: Stage means more than grade in adenoid cystic carcinoma. Am J Surg 1992, 164:623-628.

36. Li Q, Zhang XR, Liu XK, Liu ZM, Liu WW, Li H, Guo ZM: Long-term treatment outcome of minor salivary gland carcinoma of the hard palate. Oral Oncol 2012, 48:456-62.

37. Spiro RH: Distant metastasis in adenoid cystic carcinoma of salivary origin. Am J Surg 1997, 174:495-498.

38. Halsted WS: The results of radical operations for the cure of carcinoma of the breast. Ann Surg 1907, 46:1-19.

39. Fisher B: Biological research in the evolution of cancer surgery: a personal perspective. Cancer Res 2008, 68:10007-10020.

40. Weichselbaum RR, Hellman S: Oligometastases revisited. Nature Rev Clin Oncol 2011, 8:378-382.

41. Ballonoff A, Raben D, Rusthoven KE, Bassetti M, Kane M, Song Jl, Chen C Outcomes of patients with $\mathrm{n} 3$ neck nodes treated with chemoradiation. Laryngoscope 2008, 118:995-998.

doi:10.1186/1477-7819-10-266

Cite this article as: Lee et al:: Prognostic value of expression of molecular markers in adenoid cystic cancer of the salivary glands compared with lymph node metastasis: a retrospective study. World Journal of Surgical Oncology 2012 10:266.

\section{Submit your next manuscript to BioMed Central and take full advantage of:}

- Convenient online submission

- Thorough peer review

- No space constraints or color figure charges

- Immediate publication on acceptance

- Inclusion in PubMed, CAS, Scopus and Google Scholar

- Research which is freely available for redistribution 